\title{
Territorio distante y Ensayos Pedagógicos
}

Lidia Blanco ${ }^{1}$

La reflexión, el análisis, la crítica y la profundización en los distintos tópicos que se manejan en nuestras sociedades, son una labor obligada si queremos mantenernos lúcidos ante la permanente manipulación que de esos tópicos realizan los distintos poderes. El pensamiento en español, al contrario de lo que podría parecer, tiene una larga tradición en cada uno de nuestros países y apoyando la crítica irónica que Caetano Veloso lanza cuando canta «sólo es posible filosofar en alemán", podemos mostrar los millones de ensayos que desde distintas geografías de los espacios hispanos, nos han ayudado a mantener una mirada inteligente y distante ante la realidad que se nos impone. El ensayo es quizá la estructura básica que el idioma español ha elegido durante toda su historia para dar viabilidad al

Palabras de Lidia Blanco, directora del Centro Cultural de España. en la presentación del primer númeto de Ensayos Pedagógicos y la edición especial de esta serie, Temisorio distante: el encuentro entre la gente y la naturaleza. 
pensamiento crítico y en esta larga tradición se inscriben hoy estos dos libros.

A partir de Ensayos Pedagógicos, se nos abren distintas llamadas de atención ente los análisis que de la violencia, las actitudes sexistas, la xenofobia o la búsqueda de la igualdad de oportunidades para la diversidad de individuos, hacen Pilar Lledó, Roxana Reyes Rivas, Sara Ulloa y Enriqueta Zúniga Chaves, respectivamente. Aprendemos mucho más sobre bioética con Ana Rodríguez Allen y José Miguel Esquivel. Miramos de una forma más connotativa y simbólica el espacio que abarcamos, después de leer el trabajo de Xenia Pacheco Soto. Se rompen algunas telarañas que nos construye el poder con el análisis vehemente que Carmen Rojas hace de un informe publicado por el Programa de las Naciones Unidas para el Medio Ambiente. Yo aprendo un mito y nuevos nombres con Grace Prada Ortiz que me presenta a la maestra Rudecinda, a Manuelita Escalante y a Ester Silva; y con Marta Ávila Aguilar me introduzco en la danza costarricense y me lleno de ganas por saber más. Después de leer a Carlos Sandoval García no sólo conocemos muchos más de los procesos de globalización y del papel de las universidades en esos procesos, sino que además tenemos un mapa claro de las posibilidades que estas universidades tienen de incidir tanto en el estancamiento de los efectos negativos de esta globalización, como en proponer soluciones activas que se adelanten a esos efectos. Con Gerardo Cordero, Maurizia D Antoni y Lorena Vargas conocemos otras miradas hacia temas tan distintos como la solidaridad cristiana, la enseñanza de un idioma o la literatura de Juan Rulfo. Todo esto en apenas 200 páginas, en apenas una mañana de lectura más que agradable y placentera. ¿Qué más se puede pedir?.

Territorio Distante de Ángeles Arenas, Matilde Mordt y Filemón Ríos, es otro ejemplo de lo que puede enseñar un 
estudio pormenorizado de un territorio apenas perceptible en los mapas, «Los Guatuzos», tan cercano a Costa Rica y a Nicaragua y tan distante como ya desde el título señalan los autores. El análisis exhaustivo de su historia, su entramado social, su economía y la convivencia con el medio ambiente, intercalado con notas de viaje de los autores y con las voces directas de los protagonistas hacen que este libro sea, no sólo un sólido trabajo de investigación, no sólo una entretenida lectura, sino y sobre todo un ejemplo extrapolable, al menos en conceptos, a muchas otras zonas geográficas. La zona escogida tiene características bien definidas: zona fronteriza, población flotante y población arraigada, agricultura de subsistencia y refugio ecológico. Binomios que si bien en el libro se estudian como características propias de los Guatuzos, ponen sobre el tapete las grandes contradicciones entre el desarrollo y la conservación, la propiedad y el derecho a la tierra, la subsistencia del hombre y el ambiente, el desarrollo sostenible y la protección económica. Problemas todos ellos por solucionar y que se irán acrecentando, si no se ponen soluciones, cuanto más avance la mal llamada globalización que no tiene en cuanta la diversidad si ésta no se encuentra en los límites de la riqueza.

Quiero terminar, de nuevo agradeciendo esta oportunidad de aprendizaje que he tenido con la lectura de estos dos libros y animándoles, a todos los que no o hayan hecho ya, a leerlos y a seguir contribuyendo al pensamiento lúcido y crítico para intentar ser cada día mejores y más conscientes del mundo en que vivimos y en el que podemos un día llegara vivir. 